\title{
Where are we now?
}

As the new year started, this caught my eye in my daily trawl of online news: 'Potato-rich diet "may increase pregnancy diabetes risk"'. This BBC news item, based on an article ${ }^{[1]}$ in the British Medical Journal, suggests that women who eat potatoes in any form most days of the week have an increased risk of diabetes during pregnancy. The risk is probably triggered by the massive rise in blood sugar levels that all starchy carbohydrates cause. But the interesting thing about the news item was not so much the potentially increased risk of gestational diabetes caused by eating potatoes daily, but the comment of 'British experts' who said the 'proof was lacking' and that people need to eat lots of starchy foods for fibre, as well as fresh fruit (known to be high in sugars) and vegetables. The UK advice is that people should get about one-third of their daily intake from starchy foods such as potatoes, and there is no limit to how much carbohydrate people should eat.

Another major issue in the news overseas is the idea of taxing sugary drinks, since these are now thought to be a major cause of obesity in the UK and the USA - although there is little actual evidence of direct causality. Mexico has apparently already put a tax on sugary drinks and the indications are that there may be a decrease in consumption, although it is probably too early to say, and certainly too early to see any public health benefits. A recent Lancet $\operatorname{article}^{[2]}$ modelling a reduction in sugar in carbonated drinks and fruit juices over a period of 5 years (without replacing the sugar with artificial sweeteners) suggests that this could significantly reduce levels of obesity and type 2 diabetes. But the assumption again is that it is specifically sugar that is the main culprit in both conditions.

So, where are we now? We have a situation where people are slowly starting to become aware of the amount of sugar in carbonated drinks and fruit juices, and possibly also added sugar in other foods generally. 'Experts' are telling them this is bad and that people must cut down on the amount of sugar in their diets. But at the same time these same 'experts' are telling people that saturated fat is still bad and, on top of this, that people must eat lots of starchy foods because of the fibre content. Both the UK ${ }^{[3]}$ and US ${ }^{[4]}$ dietary guidelines were updated in 2015, but you could be forgiven for thinking that little has changed - this in spite of the great fanfare around cholesterol no longer being demonised when the USA guidelines were released. All these guidelines actually said was that dietary cholesterol was no longer thought to cause increased blood cholesterol, so people could stop worrying about eating eggs. As in the UK guidelines, starchy foods are still recommended as a major part of the diet, in the main because of their fibre content. And, as in the UK guidelines, saturated fat is still enemy number one.

As Nina Teicholz, writing in the $B M J$ last year, ${ }^{[5]}$ said: 'The expert report underpinning the next set of US Dietary Guidelines for Americans fails to reflect much relevant scientific literature in its reviews of crucial topics and therefore risks giving a misleading picture ... The omissions seem to suggest a reluctance by the committee behind the report to consider any evidence that contradicts the last 35 years of nutritional advice.' Much the same could be said of the many commentators on the various news items that the lay press cull from the academic journals. Whenever a study suggests that starchy foods are a problem or that saturated and other fats are a necessary and desirable part of the diet, conventional wisdom comes to the fore and the advice of the past 35 years is once again uncritically trundled out.

It has struck me in my foraging through both lay and academic literature over the past couple of years that the change in the way that our food is produced - largely as a result of the initiation of the guidelines of 35 years ago - has spawned not only major research drives aimed at trying to defeat the surge of obesity and related diseases, but the rise and rise of the pharmaceutical companies that are exploiting the potential for drug treatment of diseases that are diet related. And all we need to do is eat real food.

\section{Bridget Farham}

Acting Editor

ugqirha@iafrica.com

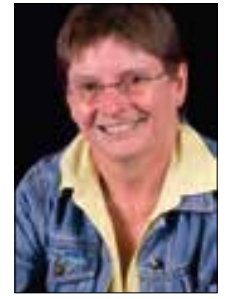

1. Bao W, Tobias DK, Hu FB, Chavarro JE, Zhang C. Pre-pregnancy potato consumption and risk of gestational diabetes mellitus: Prospective cohort study. BMJ 2016;352:h6898. DOI:10.1136/bmj.h6898 gest $\mathrm{Y}, \mathrm{He}$ FJ Yin Y H substitution as a strategy to reduce overweight, obesity, and type 2 diabetes: A modelling study. Lancet
s. substitution as a strategy to reduce overweight, obesity, and type 2 diabetes: A n
Diabetes Endocrinol 2016;4(2):105-114. DOI:10.1016/S2213-8587(15)00477-5

3. Scientific Advisory Committee on Nutrition. Carbohydrates and Health. London: The Stationery 3. Scientific Advisory Committee on Nutrition. Carbohydrates and Health. London: The Stationery
Office, 2015. https://www.gov.uk/government/uploads/system/uploads/attachment_data/file/445503/ SACN_Carbohydrates_and_Health.pdf (accessed 10 March 2016).

4. Dietary Guidelines Advisory Committee. Scientific report. 2015. http://health.gov/ dietaryguidelines/2015-scientific-report/ (accessed 10 March 2016).

5. Teicholz N. The scientific report guiding the US dietary guidelines: Is it scientific? BMJ 2015;351:h4962. DOI:10.1136/bmj.h4962

S Afr Med J 2016;106(4):314. DOI:10.7196/SAMJ.2016.v106i4.10764 